Adolescents' Responses to Warning Tobacco Labels

\title{
Emotional Impact and Perceived Effectiveness of Text-Only versus Graphic Health Warning Tobacco Labels on Adolescents
}

\author{
Pedro Margalhos ${ }^{1}$, Francisco Esteves ${ }^{2}$, Jaime Vila ${ }^{3}$, and Patrícia Arriaga ${ }^{4}$ \\ ${ }^{1}$ Instituto Superior Manuel Teixeira Gomes - ISMAT (Portugal) \\ ${ }^{2}$ Mid Sweden University (Sweden) \\ ${ }^{3}$ Universidad de Granada (Spain) \\ ${ }^{4}$ ISCTE-Instituto Universitário de Lisboa (Portugal)
}

\begin{abstract}
Correspondence concerning this article should be addressed to Patrícia Arriaga. ISCTEInstituto Universitário de Lisboa, CIS-IUL. Departamento de Psicologia Social e das Organizações. Av ${ }^{\mathrm{a}}$ das Forças Armadas, Edifício ISCTE. 1649-026 Lisboa (Portugal). Email: patricia.arriaga@iscte-iul.pt
\end{abstract}

\section{How to cite this article:}

Margalhos, P., Esteves, F., Vila, J., \& Arriaga, P. (2019). Emotional impact and perceived effectiveness of text-only versus graphic health warning tobacco labels on adolescents. The Spanish Journal of Psychology, 22. eXX. doi:XXXX.

\section{Authors' note}

This study was funded by Fundação Calouste Gulbenkian (grant number: 95476) and by the Portuguese Foundation for Science and Technology through the Research Center CIS-IUL (Ref. UID/PSI/03125/2013). 


\begin{abstract}
The study of smoking in adolescence is of major importance as nicotine dependence often begins in younger groups. Tobacco health warnings have been introduced to inform people of the negative consequences of smoking. This study assessed the emotions and perceived effectiveness of two formats of tobacco warnings on adolescents: Text-only versus graphic warning labels. In addition, we analyzed how emotions predicted their perceived effectiveness. In a cross-sectional study, 413 adolescents (131 smokers, 282 non-smokers) between 13-20 years of age rated their emotions (valence and arousal) and perceived effectiveness towards a set of tobacco warnings. Results showed that graphic warnings evoked higher arousal than text-only warning labels $(p=.038)$. Most of the warning labels also evoked unpleasantness with smokers reporting higher unpleasantness regarding textonly warnings compared to non-smokers $(p=.002)$. In contrast, perceived effectiveness of the warnings was lower in smokers than in non-smokers $(p=.029)$. Finally, high arousal and being a non-smoker explained 14\% of the variance of perceiving the warnings more effective. Given the role that warnings may play in increasing health awareness, these findings highlight how smoking status and emotions are important predictors of the way adolescents consider tobacco health labels to be effective.
\end{abstract}

Keywords: adolescents, emotions, perceived effectiveness, tobacco health labels. 
Smoking is considered a high-risk activity for public health and one of the leading causes of preventable death (World Health Organization, 2017). We have seen a reduction in tobacco consumption in most European countries, partly attributed to a better dissemination of information about the risks and the consequences associated with tobacco intake, in line with several legislative initiatives that are assumed to control the tobacco consumption among citizens. Amongst these initiatives are the regulations on the labelling of tobacco products in order to disseminate health information and increase awareness about the hazards of tobacco consumption by including written health messages or combined text-plus-graphic warnings in the packages.

The first legislative measure concerning health warning labelling implemented by the European Community was introduced in 1989 with the Directive 89/622 for the inclusion of rotating text-only warnings messages on the cigarette packs. In 2003 a series of pictorial warnings were developed to be used on tobacco packages, and in 2004 the European Union's ASPECT consortium recommended that text-plus-graphic warning labels should be "mandatory on both sides of all tobacco products" (ASPECT Consortium, 2004, p. 23). According to a recent report by the World Health Organization (2017), graphic pack warnings has become the policy measure most widely implemented worldwide, with 78 countries adopting this measure (47\% of the global population).

Several theories and research have shown that emotions can be one of the main causes of action (Frijda, 2010), suggesting that they can be an important predictor of motivational and behavioral responses to health warning labels (Bekalu, Ramanadhan, Bigman, Nagler, \& Viswanath, 2018; Evans et al., 2017, McNeill et al., 2018). One contribution to understand the emotional impact of visual displays comes from Lang's bio-informational model (Lang, 1995), according to which emotions are dispositions to action that reflect an engaged motivational system. A key assumption in Lang's model is that the neural circuits underlying emotion have direct connections to the brain's two primary motivational systems: The appetitive-approach system, which is associated with pleasant emotions; and the defensiveavoidance system, which is associated with unpleasant emotions (Bradley, Codispoti, Cuthbert, \& Lang, 2001). Thus, the impact of tobacco warning labels, as well as their effect on negative attitudes toward tobacco consumption, can be assessed in the context of these two motivational systems. Depending on their emotional impact, warning labels assessed as 
being very unpleasant and highly arousing may contribute to an increased attention and negative attitudes towards consumption, thereby enhancing the effectiveness of these campaigns (e.g., Bekalu et al., 2018; Evans et al., 2017). This perspective is consistent with several fear appeal theories and results from some meta-analyses (e.g., Witte \& Allen, 2000) which suggest that the ability of a threatening message to persuade behavior change seems to be associated with the level of negative emotional response it elicits.

Overall, research has shown that both unpleasant text-only labels and text-plusgraphic warnings (herein simply referred to as "graphic" warnings) are effective tools for health dissemination. A recent meta-analysis (Noar et al., 2016), based on 37 experimental studies, indicated that graphic warnings were more effective than text-only warnings in 12 of the 17 outcomes reviewed, including attracting and holding individuals' attention, eliciting stronger negative attitudes toward smoking, increasing intentions to not start smoking and to reduce or quit consumption, and stronger emotional responses such as fear.

Despite the findings supporting the inclusion of graphic warnings relative to text-only labels on tobacco products, the study conducted by Evans et al. (2017) suggested that not all graphics produce the same positive results and highlighted the need to consider the emotional arousal triggered by the warnings. The authors conducted an experiment in which adolescents (14-18 years old) and adults (19-64 years old) were exposed over 2 weeks to three type of warnings: Text-only warnings and graphic warnings classified as low and high in levels of emotional content. Overall, they found that text-only warnings triggered more arousal than the graphics in the low-emotion content condition, but less arousal than the graphic warnings in the high-emotion content condition. In addition, the graphics triggering high arousal increased more risk perceptions and quit intentions than text-only warnings, whereas the graphics triggering low arousal were less effective than text-only warnings in reducing risk perceptions and quit intentions. More recently, Bekalu et al. (2018) have also found that not all unpleasant emotions elicited by graphic warnings are effective and that those eliciting stronger arousal can be more effective in predicting intention to quit smoking among adult smokers of low socioeconomic position.

However, the use of fear appeals to promote behavioral changes has also been criticized for producing maladaptive reactions and defensive responses, with some studies reporting that text-plus-graphic warnings may cause strong aversiveness or avoidance of 
warnings, and more psychological reactance than text-only warnings (e.g., Hammond, Fong, McDonald, Brown, \& Cameron, 2004; LaVoie, Quick, Riles, \& Lambert, 2017; Wehbe, Basil, \& Basil, 2017). Other authors also advocated the importance of using moderate levels of fear arousal in health communication, with the assumption that very low or very high levels of negative arousal may not be effective for health communication and persuasion (e.g. Hovland, Janis, \& Kelly, 1953; Janis, 1967). However, according to the Witte and Allen's (2000) meta-analysis of fear appeals theories, no support has been found for the assumption of a curvilinear relationship between fear arousal and attitudinal change, or negative effects from fear appeals in public health campaigns. Nevertheless, some systematic reviews focusing on tobacco warnings also found no evidence for the impact of graphic warnings on behavioral outcomes, such as quit attempts and smoking cessation (Monárrez-Espino, Liu, Greiner, Bremberg, \& Galanti, 2014), nor on perceived likelihood of tobacco harm or selfefficacy to quit (Noar et al., 2016). Overall, these results indicate that warnings may produce different results depending on the levels of arousal these stimuli trigger but also the type of outcomes (e.g. emotions, intentions, behaviors).

In addition, research also needs to consider its audience, such as the role of sociodemographic characteristics, and smoking behavior. Hitchman et al. (2012), for example, examined the effectiveness of text-only warning labels across four nationally representative samples of smokers from the International Tobacco Control Project Europe Surveys (France, Germany, Netherlands, and UK). They concluded that the health warning effectiveness varied across countries. The impact tended to be highest in countries with more comprehensive tobacco control programs, among smokers with the lowest socioeconomic status, and among smokers who smoked fewer cigarettes per day and made previous attempts to quit smoking. Thus, research from different countries is needed to identify the factors that better predict the effectiveness of warning labels on consumers, including the role that emotions play in this process.

It is relevant to investigate the impact of health warnings on adolescents. Most studies conducted with adults have shown that warnings can be an effective way to communicate health risks of smoking, but less evidence has been published on adolescents. Noar et al. (2016) meta-analysis, for example, only included four studies $(11 \%)$ that focused solely on teenagers. However, according to a recent report on cigarette consumption in the USA, 
"attitudes and beliefs about cigarette smoking are no longer moving in a direction that would discourage use. This suggests that external changes in the environment may be required to further reduce youth smoking" (Johnston et al., 2018, p. 39). Thus, it is of utmost importance for policy planning to study the impact of health warning measures for prevention at early stages, given that smoking experimentation and nicotine dependence also tend to begin during adolescence, and smoking behavior seems to remain relatively stable based on habits from these early ages (Johnston et al., 2018). Moreover, studies with adolescents have been conducted in few countries. One exception is the study conducted by Andrews, Netemeyer, Burton, and Kees (2016), who tested among adolescents of three different countries (USA, Spain, France) the impact of eight versions of cigarette packages, all containing the same text label warning and brand, but manipulating the logo information (plain vs. brand logo) and the levels of vividness, powerful and intensity of the graphic warning content (classified as absent, low, medium, high graphicness) on several outcomes, including craving, fear, pack feelings, and quitting thoughts. Their findings are consistent with previous studies with adults, indicating that graphic warnings displaying high and moderate levels of vividness/powerful/intense content were more effective in predicting quit thoughts and reducing cigarette craving in adolescent smokers than graphic warnings classified low in those features, or no graphic warning. Some differences between countries were also found, including the level of fear the warnings evoked was significantly less in the French sample than in the other country samples. However, there has also been research showing that warnings with graphics may not discourage USA adolescent male smokers from wanting to smoke nor increase their risk perception of smoking hazards compared to text-only warnings (Pepper, Cameron, Reiter, McRee, \& Brewer, 2013).

Addressing potential gender differences is particularly important given that these warning may not be similarly effective for both sexes. Research suggests, for example, that women tend to perceive tobacco graphic warnings as being more unpleasant and more arousing than men (Muñoz et al., 2013), and to be more emotionally sensitive to some graphic warnings than men (e.g., stronger emotions to images depicting harm inflicted on children or animals) (Gendall, Hoek, \& Gendall, 2018). Another meta-analysis on the effectiveness of fear appeal has shown that negative appeals also tend to be more effective for women than for men, probably because women seem to be more prevention-oriented than men 
(Tannenbaum et al., 2015). However, gender differences in smoking-related behaviors may also be relevant in predicting the perceived effectiveness of these campaigns, with studies suggesting that women who smoke tend to be less self-confident in quitting and to show greater risk of relapse after cessation attempts than men (Samet, Yoon, \& World Health Organization Tobacco Free Initiative, 2001).

Conflicting results have also been reported regarding the effectiveness of graphic and text-only warning labels on smokers versus non-smokers. Noar et al. (2016) meta-analysis found that both smokers and non-smokers perceived graphic health warnings to be more effective than text-only messages, although a statistical trend suggested that non-smokers considered the warnings as more effective than smokers. Prior studies in adolescent samples also highlighted this trend. For example, Vardavas, Connolly, Karamanolis, and Kafatos (2009) have shown that, regardless the message of the warning label, non-smoking adolescents rated graphics as more effective than text-only warnings. Regarding the emotional impact, Muñoz et al. (2013) found smoking behavior to be a significant predictor in combination with age. In their study, heavy smokers between 19-20 years of age reported low unpleasantness; but one-time smokers between 15 and 16 years old reported higher arousal from exposure to graphic warnings. A recent study conducted by Gendall et al. (2018) has also shown that occasional smokers, compared to daily smokers, showed stronger emotional responses to graphic warnings. These findings are consistent with contemporary theories of fear appeals and reactance responses that smokers may develop in response to exposure to the threatening warnings (Wehbe et al., 2017). Heavy smokers may develop stronger rationalization strategies to deal with negative messages that highlight the hazards of smoking and may habituate to the threatening messages in an effort to reduce fear (Witte \& Allen, 2000).

In the present study we examined the subjective emotional responses and perceived effectiveness of exposure to custom text-only versus novel graphic health warnings on tobacco packages among Portuguese adolescents, considering their smoking behavior and gender. We hypothesized that graphic labels would evoke higher negative feelings and arousal, and to be perceived as being more effective than text-only labels. We also expected females to be more emotionally sensitive to these warning compared to males. Specifically, females would report more unpleasantness and more arousal, and would judge the warnings 
to be more effective than men. Although smokers could be more emotional sensitive to the threat of the warnings because of their direct experience with smoking (Wehbe et al., 2017), contemporary theories of fear appeal and reactance also propose that the responses to these warnings may have the opposite pattern, with smokers developing strategies to minimize their own reactions to the warnings. Because previous research has shown contradicting findings, no specific predictions were made regarding adolescents' smoking status on the outcomes. Finally, we analyzed the role of emotions, smoking status, and gender as predictors of perceived effectiveness of the tobacco warnings and expected that arousal levels would predict perceived effectiveness of the warning labels on adolescents.

\section{Method}

\section{Participants}

A convenience sample of 413 students, from the $9^{\text {th }}$ to $12^{\text {th }}$ grade, was recruited from a local public school in Lisbon, Portugal. The students came from 17 different classes in the school. Those who had missing responses about sex, age, smoking status, and main variables (arousal, valence, and perceived effectiveness) due to incomplete measures were excluded from the analyses. Listwise deletion was used as the method for treating missing values given the problems related to replacing these values with estimates. Seventy-seven participants (18.6\%) were thus excluded, leaving a total of 336 participants, aged between 13-20 years of age $(M=15.90 ; S D=1.37 ; 170$ boys and 166 girls $)$. Two hundred and twenty-seven $(66.7 \%)$ reported being non-smokers and 109 (32.4\%) smokers. The first cigarette of smokers was consumed around 14 years of age $(M=13.92 ; S D=1.93)$ and many adolescents had been smoking for almost 26 months $(M=25.76$; $S D=20.28)$, with a mean of nearly 6 cigarettes per day $(M=5.42 ; S D=3.78)$.

\section{Measures and Procedures}

We developed a study similar to Muñoz et al. (2013). However, we introduced some improvements, namely the comparison between text-only and text-plus-graphic warning labels, assessing not only emotional but also perceived effectiveness.

Smoking habits. We asked participants about their smoking status, their age when they started smoking, daily cigarette consumption, and number of years as a smoker.

Health warning labels, emotions, and perceived effectiveness. Two different sections were developed to target different set of health warning labels: Text-only and graphic 
warning labels. One questionnaire included all 16 text-only warning labels that were approved under national legislation; the other questionnaire included 36 graphic warnings featuring the same text content, which were approved to be used in cigarette packets by European Union (EU) countries, although Portugal had not implemented these graphic labels at the time the study was conducted. The current EU text-only warnings had the exact dimensions as used in most EU countries (EU Directive 2001/37/EC, 2001) and the graphic warnings were processed using the available EU graphic warnings (EU Directive 2003/641/EC, 2003).

For emotions, we assessed both the hedonic valence and the arousal intensity using the Self-Assessment Manikin scales (SAM) (Bradley \& Lang, 1994), which are based on the dimensional model of emotions (Lang, 2000). SAM is a pictorial measure with humanoid figures that allows the assessment of the continuum affective dimensions of hedonic valence, and intensity of arousal, each rated along a 9-point scale: 1 (Displeasure) to 9 (pleasure) for valence and 1 (very calm) to 9 (very aroused).

To measure perceived effectiveness, the following four questions were asked, for each warning label: "How much do you believe this warning will help a smoker to quit smoking?"; "How much do you believe this warning will help a non-smoker not to start smoking?"; "How effective is this warning in increasing people's knowledge about the consequences of smoking?"; and "How much do you believe this warning will affect the number of times smokers will think about the risks of smoking". Items are rated along a 9-point scale, ranging from 1 (never) to 9 (very much). Responses were averaged, with higher scores indicating higher perceived effectiveness of tobacco warning labels. The Cronbach's alpha coefficient for these four items was .86.

\section{Procedure}

After receiving school authorization to conduct the study, parental consent was obtained. Adolescents also gave their consent to complete the survey and were informed that they could discontinue the study, if they found it stressful or uncomfortable. Every student who volunteered completed one of two surveys: One containing the text-only and the other containing the graphic warnings. These two surveys were randomly assigned to groups of students according to their classroom where they completed the survey in group sessions (about 20-30 participants in each group). Data collection took place at different times of the 
day and in different classrooms according to the classes scheduled during a two-week period. No time limit was given to complete the survey task. Participants took on average 30 minutes to complete the survey. Among the final total sample, 181 completed the survey with textonly warnings and 155 with the graphic warning labels. All participants were debriefed and thanked for their participation.

\section{Results}

\section{Emotional Responses and Perceived Effectiveness}

We examined the emotional responses (arousal and valence) and perceived effectiveness as a function of smoking status (smokers, non-smokers), gender (male, female), and type of warning label (text-only, graphic), by conducting Univariate Analyses of Variance (ANOVAs).

The mean and standard deviation of the emotional and perceived effectiveness responses were calculated for both warning labels (see Figure 1).

(please insert Figure 1 here)

For valence, the means were relatively low $(M=4.41, S D=1.79)$, indicating that the warning labels triggered unpleasant feelings ( $<5$ on a scale ranging between $1-9$ values) for the majority of the adolescents $(n=223 ; 66.4 \%)$. The ANOVA results for valence using a 2 (warning label) X 2 (smoking status) X 2 (gender) factorial design showed a significant main effect of smoking status, $F(1,328)=4.43, p=.036, \eta_{p}^{2}=.01$, and a smoking status $\mathrm{X}$ warning labels interaction, $F(1,328)=5.85, p=.016, \eta_{p}^{2}=.02$. The main effect of smoking status indicated that warning labels evoked a higher unpleasantness in smokers $(M=4.14, S D=$ $1.57)$ than non-smokers $(M=4.54, S D=1.88)$. However, this difference only occurred for those who were exposed to the text-only warnings $\left(M_{\text {smokers }}=3.64 \pm 1.42 S D\right.$ vs. $M_{\text {non-smokers }}$ $=4.59 \pm 1.82 S D, p=.002$, Cohen's $d=0.58$ ). No significant differences were found between smokers and non-smokers in affective valence ratings for those who were exposed to the graphics warnings $\left(M_{\text {smokers }}=4.55 \pm 1.57 S D\right.$ vs. $\left.M_{\text {non-smokers }}=4.47 \pm 1.97 S D, p=.824\right)$.

For the arousal levels, the warning labels were rated in general as moderately arousing $(M=5.05, S D=1.96)$. The results of the ANOVA 2 (warning label) X 2 (smoking status) X 2 (gender) on arousal only revealed a significant main effect of warning labels, $F(1$, $328)=4.36, p=.038, \eta_{p}^{2}=.01$, indicating, as expected, that participants in the graphic warning condition reported higher arousal $(M=5.36, S D=1.75)$ than those in the text-only 
warnings condition $(M=4.78, S D=2.09)$, Cohen's $d=0.30$. This effect occurred regardless of smoking status or participant gender since no further statistically significant effects emerged.

For perceived effectiveness, the overall warning labels were rated as moderately effective $\left(M_{\text {text-only }}=5.49, S D=1.32\right)$. The 2 (warning label) $\mathrm{X} 2$ (smoking status) $\mathrm{X} 2$ (gender) ANOVA on perceived effectiveness yielded a significant effect of the smoking status, $F(1,328)=4.82, p=.029, \eta_{p}^{2}=.02$, indicating, as expected, that the warning labels were judged to be more effective for the non-smokers $(M=5.58, S D=1.25)$ than for the smokers $(M=5.32, S D=1.44)$, Cohen's $d=0.18$. In addition, the overall perceived effectiveness of the warning labels was higher for females $(M=5.61, S D=1.30)$ than for males $(M=5.37, S D=1.37)$, Cohen's $d=0.18$. No other statistically significant effects were found.

\section{Predictors of Perceived Effectiveness of Health Warning Labels}

Because we found differences in perceived effectiveness based on gender and smoking status, but no differences between the types of warnings, we conducted a simple regression analysis to investigate further the role of gender and smoking status in combination with the two dimensions of emotional responses (valence and arousal) to predict the perceived effectiveness of the warning labels. Collinearity diagnostics showed acceptable tolerance values (all >0.95), indicating that collinearity among the predictors was not a problem. As can be seen in Table 1 , only arousal $(\beta=.34, t=6.70, p<.001)$ and smoking status $(\beta=-.13, t=-2.41, p=.017)$ were significant predictors of perceived effectiveness. These variables explained $14 \%$ of the variance of perceived effectiveness in our sample of adolescents, $F(3,331)=14.46, p<.001$.

\section{(please insert Table 1 here)}

\section{Discussion}

Package warning labels are considered one of the most relevant tobacco control initiatives to inform citizens about the health consequences of smoking, as they cost little to produce and can be integrated with larger interventions in mass media campaigns.

The study of threatening warning labels as a persuasive strategy to encourage healthy behavior has been active for over 60 years. However, the effectiveness of tobacco warnings and the value of their use is still debated (Peters, Ruiter, \& Kok, 2013; Tannenbaum et al., 
2015). This study examined both emotional responses and perceived effectiveness of textonly compared to graphic health warnings on tobacco packages among Portuguese adolescents, taking into account their smoking status and gender.

Overall, the majority of the health warning labels were rated unpleasant but moderately arousing, a result that is similar to those found in previous studies (e.g. Muñoz et al., 2013). As predicted, participants reported higher arousal in the graphic condition than in the text-only condition, suggesting that adding graphic content to the warning message increase the arousal levels. This finding occurred regardless of either smoking status or gender, indicating that the novel graphics that were used in our study contributed to increase the intensity of adolescent feelings in a similar way by males and females, smokers and nonsmokers, a result also consistent with prior meta-analytic studies in this field (Noar et al., 2016). In addition, we should consider that all tobacco packages sold in Portugal have text warnings since 2003. Due to a habituation effect, the repeated exposure of participants to the text warnings, but not to the novel graphic warnings, may have contributed to the high emotional arousal reported by our sample of participants to the graphics (Haugtvedt, Schumann, Schneier, \& Warren, 1994). Results on emotional valence were also interesting. Smokers reported higher unpleasantness than non-smokers, although this difference only occurred with the text-only warnings. The result of unpleasantness in smokers to the message is in-line with the assumption that smokers would be more emotional sensitive to the warnings, as they convey threatening content related to their consumption. On the other hand, the result indicating similar levels of unpleasantness in the graphic condition for smokers and non-smokers might be also explained by the novelty of the graphics content for both groups. However, further studies should be conducted, to understand whether exposure experience to the graphics might explain this result, since prior studies in this field reported contradictory findings on emotional responses to the warnings as a function of smoking behaviour (e.g., Gendall et al., 2018; Noar et al., 2016).

In contrast with the results on emotions, we found that smokers judged the health warnings as being less effective than non-smokers did, regardless the type of warning. This result is similar to those found in previous study among adolescents (Vardavas et al., 2009) and suggests that smokers may devalue the persuasion effects of warning labels on behavioral change more strongly than non-smokers. Perhaps smokers develop counterarguing strategies, 
either passively or actively, to reduce the fear and to cope with the threatening information the warnings transmit (Wehbe et al., 2017; Witte \& Allen, 2000). This result, together with perceived emotional impact, also indicates that health warning tobacco labels may trigger different responses in the cognitive and emotional systems, suggesting a dual route of information processing.

Also relevant was the fact that females considered the warning labels more effective than males, a result consistent with prior meta-analysis on the effectiveness of fear appeals (Tannenbaum et al., 2015), suggesting that these warnings might work better with females than males, although the effect size were of low magnitude and no gender differences were found regarding the warnings' emotional impact.

In addition, the results of the regression analysis helped us understand whether gender, smoking status and emotional responses contributed to explain the perceived effectiveness of the warnings. The results suggested that only high emotional arousal and being a non-smoker accounted for the perceived effectiveness of the warning labels. These results may have important implications. First, it indicates that arousal is an important emotional dimension for the perceived effectiveness of the warning labels. This result is in line with prior studies (Evans et al., 2017; Noar et al., 2016) and with the recent findings from Bekalu et al. (2018) who concluded that beyond valence, arousal seems to be a strong factor to consider in labelling tobacco products. To make an evaluative judgment, people often rely on the intensity of their feelings and then use those feelings as an indicator of their judgment. Thus, the arousal levels in response to the health warning messages may have been the basis for their evaluative judgments. Second, these findings suggest that non-smokers judge warning labels to be more effective than smokers.

Given that one of the main purposes of these warnings is to warn smokers of the consequences of their behavior, would our findings suggesting low impact for adolescent smokers mean a failure in this undertaking? In our view, it is not possible to make this inference based on our results, because we have not measured behavioral outcomes. It is possible that smokers may have minimized the perceived effectiveness of the information displayed on tobacco packages due to rationalization strategies to cope with the threats, as suggested by contemporary theories of fear appeals or reactance (Wehbe et al., 2017). Moreover, the information provided on both sets of health warnings may not have tackled 
adolescents' concerns. Sentences like - "smoking kills" may also seem too far away from adolescents' concerns, and therefore the perceived effectiveness might have been reduced. Gendall et al. (2018) also highlighted findings from previous studies indicating that the credibility of tobacco health warnings is often questioned by young individuals who tend to consider the information in the warnings to be less reliable than their own observations of older smokers with apparent health. Thus, it is important to frame the messages with information targeting more directly the concerns of the adolescent's fears in order to increase their effectiveness. Our results are consistent with previous findings indicating that adolescents do not believe that graphic health warnings will influence adolescents who already smoke, and therefore seem to be not powerful enough to change their responses (e.g., Crawford, Balch, Mermelstein, \& the Tobacco Control Network Writing Group, 2002).

We should also consider some methodological limitations of our study. First, we chose a convenience sample, from one school localized in an urban area, which narrows the generalization of our findings. Second, we only used self-reported measures to assess emotional impact. It could be relevant to add complementing emotional indicators such as physiological responses (e.g., skin conductance responses for arousal) because they are less subject to social desirability concerns. It would also be relevant to consider the actual behavioral responses towards consumption instead of relying on perceived effectiveness. Third, we used a cross-sectional design by collecting data through surveys, instead of using an experimental or a longitudinal design, which does not allow us to make causality inferences based on this study. We should also consider that the effect sizes in our study were quite low in magnitude for the majority of the analyses, although they were medium in size for the differences found in the emotion responses (based on conventional interpretation as suggested by Cohen, 1988). The overall explained variance by both arousal and smoking status on perceived effectiveness was also relatively low (14\%), suggesting that additional studies must investigate other factors beyond the outcomes studied, to better understand how health warnings can be made more efficient for adolescents. Understanding how to create persuasive cigarette warning labels is a crucial step toward stemming the epidemic of disease and death due to tobacco use.

In summary, the current results show the emotional impact and perceived effectiveness of warning labels and suggest that a combination of graphic images and 
elaborated text is important for transmitting health information. It also indicates the need to continue identifying factors that may contribute to detachment and to focus on increasing message credibility in the information presented on the labels. This can be made by addressing the major concerns of the adolescents. Adolescents, for example, tend to initiate and continue smoking for social reasons: Peer behavior and need for approval trump risk factors for smoking among adolescents (Liu, Zhao, Chen, Falk, \& Albarracín, 2017). Thus, framing the messages in the warnings that would include references to their age and social groups should be further tested. Given the overall low impact of the warnings on our sample of adolescents, it is imperative to pursue research in this field for a better dissemination of information about the risks and the negative consequences associated with tobacco intake, in order to stop and prevent smoking in this population. 


\section{References}

Andrews, J. C, Netemeyer, R. G., Burton, S., \& Kees, J. (2016). Effects of plain package branding and graphic health warnings on adolescent smokers in the USA, Spain and France. Tobacco Control, 25, e120-e126. http://doi.org/10.1136/tobaccocontrol-2015-052583

ASPECT Consortium (2004). Tobacco or health in the European Union: Past, present and future. Luxembourg, Luxembourg: Office for Official Publications of the European Communities.

Bekalu, M. A., Ramanadhan, S., Bigman, C. A., Nagler, R. H., \& Viswanath, K. (2018). Graphic and arousing? Emotional and cognitive reactions to tobacco graphic health warnings and associated quit-related outcomes among low SEP population groups. Health Communication. Advance online publication. http://doi.org/10.1080/10410236.2018.1434733

Bradley, M. M., Codispoti, M., Cuthbert, B. N., \& Lang, P. J. (2001). Emotion and motivation I: Defensive and appetitive reactions in picture processing. Emotion, 1(3), 276-298. http://doi.org/10.1037//1528-3542.1.3.276

Bradley, M. M., \& Lang, P. J. (1994). Measuring emotion: The Self-Assessment Mannequin and the semantic differential. Journal of Behavior Therapy and Experimental Psychiatry, 25(1), 49-59. http://doi.org/10.1016/0005-7916(94)90063-9

Crawford, M. A., Balch, G. I., Mermelstein, R., \& Group, T. C. N. W. (2002). Responses to tobacco control policies among youth. Tobacco Control, 11(1), 14-19. http://doi.org/10.1136/Tc.11.1.14

Cohen, J. (1988). Statistical power analysis for the behavioral sciences. New York, NY: Routledge Academic.

Evans, A. T., Peters, E. Shoben, A. B., Meilleur, L. R., Klein, E.G., Tompkins, M. K., ... Tusler, M. (2017). Cigarette graphic warning labels are not created equal: They can increase or decrease smokers' quit intentions relative to text-only warnings. Nicotine \& Tobacco Research, 19(10), 1155-1162. http://doi.org/10.1093/ntr/ntw389

Frijda, N. H. (2010). Impulsive action and motivation. Biological Psychology, 84(3), 570-579. http://doi.org/10.1016/j.biopsycho.2010.01.005

Gendall, P., Hoek, J., \& Gendall, K. (2018). Evaluating the emotional impact of warning images on young adult smokers and susceptible non-smokers. Journal of Health Communication, 23(3), 291-298. http://doi.org/10.1080/10810730.2018.1440332

Hovland, C., Janis, I., \& Kelly, H. (1953). Communication and persuasion. New Haven, CT: Yale University Press.

Hammond, D., Fong, G. T., McDonald, P. W., Brown, K. S., \& Cameron, R. (2004). Graphic Canadian cigarette warning labels and adverse outcomes: Evidence from Canadian smokers. American Journal of Public Health, 94, 1442-1445. http://doi.org/10.2105/AJPH.94.8.1442

Haugtvedt, C. P., Schumann, D. W., Schneier, W. L., \& Warren, W. L. (1994). Advertising repetition and variation strategies: Implications for understanding attitude strength. Journal of Consumer Research, 21(1), 176-189. http://doi.org/10.1086/209391

Hitchman, S. C., Mons, U., Nagelhout, G. E., Guignard, R., Mcneill, A., ... Fong, G. T. (2012). Effectiveness of the European Union text-only cigarette health warnings: Findings from four countries. European Journal of Public Health, 22(5), 693-699. http://doi.org/10.1093/eurpub/ckr099

Janis, I. L. (1967). Effects of fear arousal on attitude change: Recent developments in theory and experimental research. In L. Berkowitz (Ed.), Advances in experimental social psychology (Vol. 3, pp. 166-225). New York, NY: Academic Press.

Johnston, L. D., Miech, R. A., O’Malley, P. M., Bachman, J. G., Schulenberg, J. E., \& Patrick, M. E. (2018). Monitoring the future. National survey results on drug use 1975-2017: Overview, key findings on adolescent drug use. Ann Arbor, MI: The University of Michigan, Institute for Social Research. 
Lang, P. J. (1995). The emotion probe: Studies of motivation and attention. American Psychologist, 50(5), 372-385. http://doi.org/10.1037/0003-066X.50.5.372

Lang, P. J. (2000). Emotion and motivation: Attention, perception, and action. Journal of Sport \& Exercise Psychology, 22, S122-S140. http://doi.org/10.1123/jsep.22.s1.s122

LaVoie, N. R., Quick, B. L., Riles, J. M., \& Lambert, N. J. (2017). Are graphic cigarette warning labels an effective message strategy? A test of psychological reactance theory and source appraisal. Communication Research, 44(3), 416-436. http://doi.org/10.1177/0093650215609669

Liu, J., Zhao, S., Chen, X., Falk, E., \& Albarracín, D. (2017). The influence of peer behavior as a function of social and cultural closeness: A meta-analysis of normative influence on adolescent smoking initiation and continuation. Psychological Bulletin, 143(10), 10821115. http://doi.org/10.1037/bul0000113

McNeill, A., Gravely, S., Hitchman, S., Bauld, L., Hammond, D., \& Hartmann-Boyce, J. (2018). Tobacco packaging design for reducing tobacco use: Cochrane systematic review. Tobacco Induced Diseases, 16(1), A183. http://doi.org/10.18332/tid/84186

Monárrez-Espino, J., Liu, B., Greiner, F., Bremberg, S., \& Galanti, R. (2014). Systematic review of the effect of pictorial warnings on cigarette packages in smoking behavior. American Journal of Public Health, 104(10), e11-e30. http://doi.org/10.2105/AJPH.2014.302129

Muñoz, M. A., Viedma-del-Jesus, M. I., Rossello, F., Sanchez-Nacher, N., Montoya, P., \& Vila, J. (2013). The emotional impact of European tobacco-warning images. Tobacco Control, 22(2), 123-129. http://doi.org/10.1136/tobaccocontrol-2011-050070

Noar, S. M., Hall, M. G., Francis, D. B., Ribisl, K. M., Pepper, J. K., \& Brewer, N. T. (2016). Pictorial cigarette pack warnings: A meta-analysis of experimental studies. Tobacco Control, 25, 341-354. http://doi.org/10.1136/tobaccocontrol-2014-051978

Pepper, J. K., Cameron, L. D., Reiter, P. L., McRee, A.-L., \& Brewer, N. T. (2013). Non-smoking male adolescents' reactions to cigarette warnings. PLOS ONE 8(8), e65533. http://doi.org/10.1371/journal.pone.0065533

Peters, G.-J. Y., Ruiter, R. A. C., \& Kok, G. (2013). Threatening communication: A critical reanalysis and a revised meta-analytic test of fear appeal theory. Health Psychology Review, 7, S8-S31. http://doi.org/10.1080/17437199.2012.703527

Samet, J. M, Yoon, S. Y., \& World Health Organization Tobacco Free Initiative (2001). Women and the tobacco epidemic: Challenges for the 21st century. Geneva, Switzerland: World Health Organization.

Tannenbaum, M. B., Hepler, J., Zimmerman, R. S., Saul, L., Jacobs, S., Wilson, K., \& Albarracín, D. (2015). Appealing to fear: A meta-analysis of fear appeal effectiveness and theories. Psychological Bulletin, 141(6), 1178-1204. http://doi.org/10.1037/a0039729

Vardavas, C. I., Connolly, G., Karamanolis, K., \& Kafatos, A. (2009). Adolescents perceived effectiveness of the proposed European graphic tobacco warning labels. European Journal of Public Health, 19(2), 212-217. http://doi.org/10.1093/eurpub/ckp015

Wehbe, M. S., Basil, M., \& Basil, D. (2017). Reactance and coping responses to tobacco counteradvertisements. Journal of Health Communication, 22(7), 576-583. http://doi.org/10.1080/10810730.2017.1329853

Witte, K., \& Allen, M. (2000). A meta-analysis of fear appeals: Implications for effective public health campaigns. Health Education \& Behavior, 27, 591-615. http://doi.org/10.1177/109019810002700506

World Health Organization (2017). WHO report on the global tobacco epidemic, 2017: Monitoring tobacco use and prevention policies. Geneva, Switzerland: Author. 
Table 1.

Results of Stepwise Multiple Regression Analyses to Predict Perceived Effectiveness of Warning Labels

\begin{tabular}{|c|c|c|c|c|c|c|}
\hline \multirow[b]{2}{*}{ Predictors } & \multicolumn{2}{|c|}{$\begin{array}{l}\text { Unstandardized } \\
\text { Coefficients }\end{array}$} & \multirow{2}{*}{$\begin{array}{c}\text { Standardized } \\
\text { Coefficients }\end{array}$} & \multirow[b]{2}{*}{$t$} & \multirow[b]{2}{*}{$R_{\text {ajust }}^{2}$} & \multirow[b]{2}{*}{$F$} \\
\hline & $B$ & $S E$ & & & & \\
\hline (Constant) & 4.18 & 0.34 & & 12.17 & .14 & $14.46 * *$ \\
\hline Gender & .20 & 0.14 & 0.08 & 1.45 & & \\
\hline $\begin{array}{l}\text { Smoking } \\
\text { Status }\end{array}$ & -.35 & 0.15 & -0.13 & $-2.41 *$ & & \\
\hline Valence & .07 & 0.04 & 0.10 & 1.95 & & \\
\hline Arousal & .23 & 0.03 & 0.34 & $6.70 * *$ & & \\
\hline
\end{tabular}

Note. Smoking Status ( 1 = non-smokers; 2 = smokers $)$ and Gender ( 1 = Male; 2 = Female $)$ were entered dummy variables.

$* p<.05 . * * p<.001$. 
Figure 1. Means of Emotional Responses and Perceived Effectiveness as a Function of the Type of Warning Labels and of the Smoking Status.

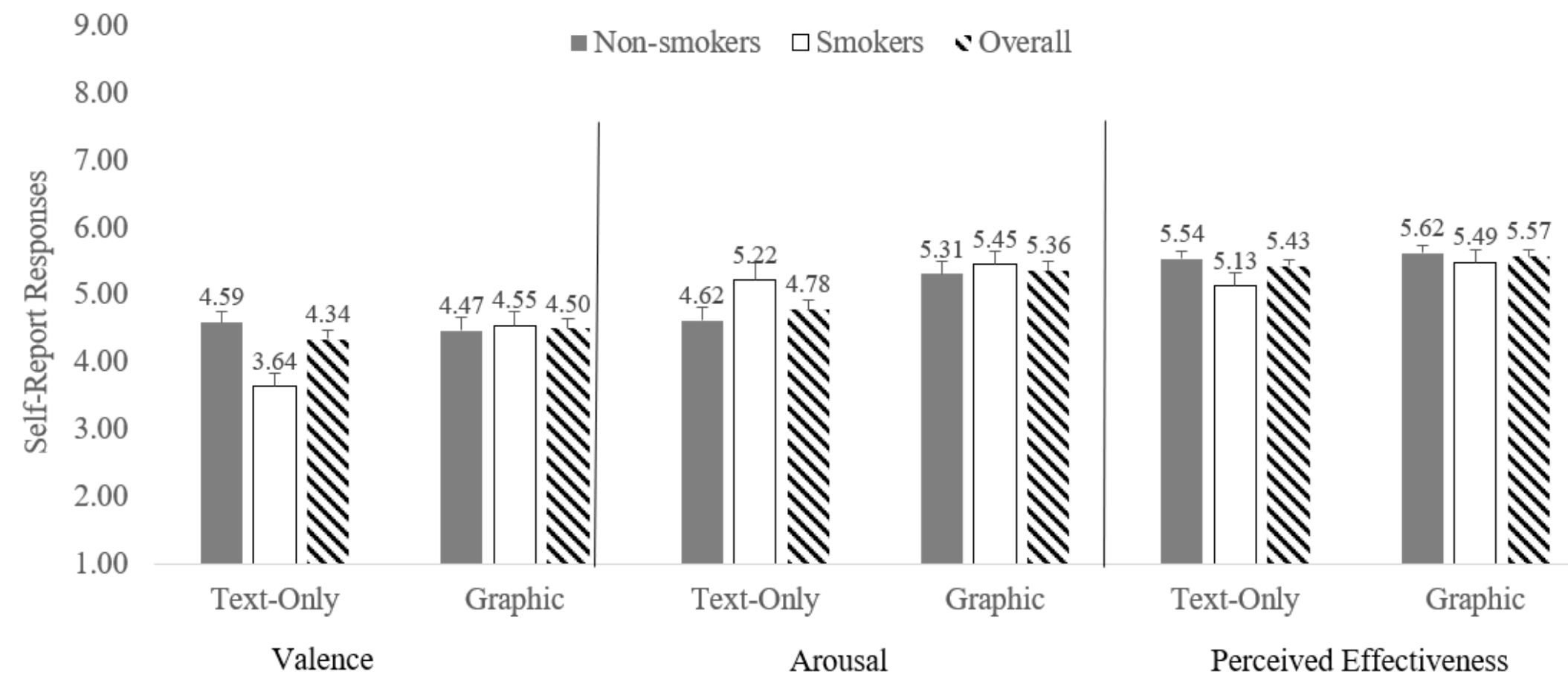

Note. The error bars represent the standard error of the means. 